\title{
Educação integral em tempo integral: o bairro como território educativo
}

\author{
Integral education in full time: \\ the neighborhood as an educational territory
}

\author{
Educación integral a tiempo completo: \\ el barrio como territorio educativo
}

\author{
Daniel Rômulo de Carvalho Rocha ${ }^{2}$ \\ Maria Celeste Reis Fernandes de Souza ${ }^{3}$
}

\begin{abstract}
Resumo: O artigo tem como cenário o debate da educação integral/tempo integral que convoca as escolas a uma maior abertura para a cidade e apresenta resultados de uma pesquisa que cartografa territórios educativos em um bairro da cidade de Governador Valadares. O aporte teórico se sustenta em autores que abordam a educação integral e nos estudos de Henri Lefebvre, Paul Claval e Michel de Certeau. Os dados foram coletados por meio de documentos e observação caminhante. Os resultados apontam um bairro com praças e ruas com pouca circulação de pessoas e de práticas cotidianas de moradores. As conclusões destacam a necessidade da garantia do direito à cidade e refletem sobre a importância de um maior diálogo entre a escola e o bairro, que pode se converter em território de aprendizagens cidadãs.
\end{abstract}

Palavras-chave: Educação integral. Tempo Integral. Território Educativo.

\begin{abstract}
This study has a scenery, the full time/Integral Time education debate that summons the schools for a great overture to the city, and it presents results of a research that maps educational territories in a neighborhood of Governador Valadares city. The theoretical contribution is supported by authors that approach the Fulltime/Integral education and also by studies of Henry Lefebvre, Paul Calva and Michel de Cordeaux. Data was collected through documents and walking observation. The results point to a neighborhood which has parks and streets with little flow of people and few everyday practices of its people. The conclusion highlights the need to guarantee the right to the city, and reflects on the importance of a greater dialogue between the school and the neighborhood, that can be converted into a territory of learning of the cities.
\end{abstract}

Keywords: Full time Education. Integral Education. Educational Territory.

Resumen: El artículo tiene como escenario el debate de la educación integral/tiempo integral, que convoca las escuelas a una mayor apertura a la ciudad, y presenta resultados de una investigación que mapea territorios educativos en un barrio de la ciudad de Governador Valadares. El aporte teórico sustentase en autores que abordan la educación integral y en los estudios de Henri Lefebvre, Paul Claval y Michel de Certeau. Los datos fueran colectados por medio de documentos y observación caminante. Los resultados apuntan un barrio con plazas y calles con poca circulación de personas, y prácticas cotidianas de residentes. Las conclusiones destacan la necesidad de la garantía del derecho a la ciudad, y reflejan a respecto de la importancia de un mayor diálogo entre la escuela y el barrio, que puede convertirse en territorio de aprendizajes ciudadanas.

Palabras clave: Educación integral. Tiempo integral. Territorio Educativo.

\footnotetext{
${ }^{1}$ Submetido em: 11 jul. 2018 - Aceito em: 21 fev. 2019 - Publicado em: 10 out. 2019.

${ }^{2}$ Secretaria Municipal de Educação de Governador Valadares - E-mail: danielromulo@ hotmail.com

${ }^{3}$ Universidade Vale do Rio Doce (UNIVALE) - E-mail: celeste.br@gmail.com
} 


\section{Introdução}

Nos últimos anos, o debate sobre educação integral/tempo integral vem se consolidando no país, respaldado por documentos legais (BRASIL, 2014) e são várias as experiências relatadas em diferentes estudos que buscam aliar ao tempo diário a mais na escola, além das tradicionais disciplinas escolares, a oferta de outras atividades que contribuam para a formação cultural, ética, estética e cidadã dos alunos (MOLL, 2012; 2014).

Os princípios que garantem esta nova dinâmica escolar podem ser identificados na Constituição Federal, no reconhecimento da educação como direito universal e igualitário (BRASIL, 1988) e, posteriormente, encontram-se na Lei de Diretrizes e Bases da Educação Nacional (BRASIL, 1996) que prevê a ampliação de jornada escolar diária, reafirmando esse direito.

Nesse sentido, no ano de 2007, o Ministério da Educação implantou o Programa Mais Educação (PME) como estratégia indutora para a ampliação do tempo diário de permanência na escola e, inspirado no movimento das cidades educadoras ${ }^{\mathrm{i}}$, convocava a escola para uma maior abertura a outros espaços de aprendizagem (BRASIL, 2007; MOLL, 2012).

Em que pesem as críticas ao PME, como a adoção do trabalho voluntário de monitores contratados pelas escolas para as atividades de educação integral, no turno ou contraturno escolar, ou a própria afiliação ao movimento das cidades educadoras europeias "que envolveriam a diversificação e a ampliação das responsabilidades educacionais para além da escola e que seriam inadequados ao tipo de organização sócio urbana das populações e cidades brasileiras" (CAVALIERE, 2014, p. 160), há que se reconhecer que o PME possibilitou ampliar a jornada escolar e incorporou ao repertório linguístico, no campo da educação, termos e expressões como "cidade educadora", "abertura da escola à cidade", "território educativo", "gestão intersetorial do território".

Conforme dados do Censo da Educação Básica referentes ao ano de 2016, o número de matrículas em tempo integral no país apresentou uma redução com relação aos anos anteriores (INEP, 2017) e, nesse mesmo ano, o PME foi substituído pelo "Novo Mais Educação" (BRASIL, 2016). Se, por um lado, esse novo programa mantém a ampliação da jornada escolar como estratégia para melhoria da aprendizagem de crianças e adolescentes por meio de atividades de acompanhamento pedagógico em Língua Portuguesa e Matemática e de atividades de arte, cultura, esporte e lazer, com vistas à melhoria do desempenho educacional. Por outro lado, retira da discussão a incorporação dos termos linguísticos acima, que traziam novos debates para as escolas, um deles, pelo qual nos interessamos neste texto, é o reconhecimento do bairro e da cidade como potenciais territórios educativos.

Nesse cenário, situamos a política de educação municipal da cidade de Governador Valadares que, no ano de 2010, garantiu o direito à ampliação da jornada escolar, implantando a Escola em Tempo Integral (ETI) de forma universalizada, nas 51 unidades escolares, para todas as crianças e todos os adolescentes matriculados na Educação Infantil e no Ensino Fundamental. Como educadores e pesquisadores temos acompanhado o processo de implementação da ETI nesses oito anos e, em que pese os avanços desta política, como a 
universalização, a preocupação com a jornada integral para professores, a construção de diretrizes curriculares específicas, as parcerias com o PME, preocupa-nos o pouco diálogo desta proposta com a cidade, conforme outros estudos têm apontado (UFMG, 2012; SOUZA; CHARLOT, 2016).

O texto se insere, pois, nesse conjunto de debates e reafirma o direito ao tempo integral e a importância de maior abertura da escola para o entorno e a cidade. Nesse sentido, compartilha resultados de uma pesquisa cujo objetivo foi explorar o potencial educativo de um bairro da cidade de Governador Valadares. O estudo é balizado em autores que discutem a educação integral e nas contribuições de Henri Lefebvre, Paul Claval, Michel de Certeau e colaboradores, que inspiraram o processo de observação caminhante utilizado como metodologia para apreender os territórios educativos no bairro analisado.

\section{Aporte teórico e metodológico}

O PME, como parte da agenda de ampliação da jornada escolar no Brasil, em suas diferentes edições até o ano de 2015, organizava a ampliação da jornada escolar na oferta de atividades que implicavam no estreitamento das relações entre escola e comunidade, privilegiando os saberes comunitários e as atividades de maior participação dos estudantes. Além do acompanhamento pedagógico previa atividades de experimentação e investigação científica, cultura e arte, esporte e lazer, cultura digital, educação econômica, comunicação e uso de mídias, meio ambiente, direitos humanos, práticas de prevenção aos agravos à saúde, promoção da saúde e da alimentação saudável (BRASIL, 2010a).

Nos fundamentos do PME (anterior a 2016), podem ser identificados o binômio educação integral/tempo integral, pela intencionalidade explícita dos macrocampos a uma maior abertura do currículo escolar, e também porque o Programa colocava em pauta a ampliação dos espaços reconhecidos como educativos, para além da escola:

[...] o Mais Educação fomenta e financia atividades propostas, organizadas e coordenadas pela escola e que aconteçam em espaços significativos da vida do bairro e da cidade, estimulando a experiência cultural e civilizatória do cinema, do teatro, do museu, dos parques, das praças, entre outros, como parte da ação curricular da escola (MOLL, 2014, p. 25).

É nesse contexto de debates que o termo território educativo começa a fazer seu comparecimento. Defende-se que o entorno da escola, "a comunidade", é educativo pela presença de diferentes atores sociais e práticas socioculturais que podem dialogar de modo mais efetivo com o currículo escolar (MOLL, 2012; 2014).

O documento "Educação Integral: texto referência para o debate nacional" (BRASIL, 2009a), reafirma a necessidade de uma maior abertura da escola para outros espaços da cidade e apresenta territórios educativos como "culturais", posto que tecidos em práticas sociais, e que, portanto, podem e devem se articular ao currículo escolar.

É nesse conjunto de debates que articula cidade, território e escola que elegemos como aporte teórico as contribuições de Lefebvre $(1999$; 2001) sobre o direito à cidade, de 
Paul Claval (2007; 2012; 2014) sobre território e de Michel de Certeau (2012; 2013; 2014) que nos permitem compreender as práticas cotidianas como atitudes culturais dos praticantes ordinários da cidade.

Lefebvre (1999) enfatiza que a cidade, em sua totalidade e complexidade, deve ser compreendida como um todo e, nesse sentido, deve ser "apreendida e re-apreendida" (LEFEBVRE, 1999, p. 16) diariamente, pelos seus habitantes como um direito, posto que o espaço urbano se constitui como espaço de relações.

O autor defende que a cidade, além garantir o direito aos seus cidadãos de ir e vir, deve também possibilitar que as pessoas tenham livre acesso a todos os espaços de forma digna, de modo que o cidadão possa transitar do bairro mais nobre ao mais periférico e deve reconhecer, tanto em um quanto em outro, os significados para aqueles que neles habitam (LEFEBVRE, 1999).

Nesse exercício de reconhecer a cidade "de direito", como um território que ensina e que se constitui por meio das práticas sociais, ela se apresenta como um organismo vivo, posto que nela vivem cidadãos e cidadãs, o que empresta à mesma uma dinâmica a ser compreendida e respeitada.

Pensar a cidade como um direito e como um território formado por símbolos, atitudes, modos de viver, nos aproxima de Paul Claval. O território, em uma abordagem cultural como propõe o autor, considera o estudo do ser humano (crianças, adolescentes, jovens, adultos, homens e mulheres) como eixo central da constituição da identidade e construção coletiva da cultura de um povo. Assim, o sujeito traz consigo uma cultura que dá "sentido à vida individual e coletiva" (CLAVAL, 2012, p. 98).

Remetendo ao autor citado, há uma conjunção entre cidade - território - cultura, defendida neste tripé que reflete "significações de espaço para cada indivíduo e da maneira de construir objetos sociais a partir das experiências sociais" (CLAVAL, 2007, p. 98).

Pode-se afirmar, pois, que o território, na perspectiva cultural, se estabelece por meio das interações sociais. Os aspectos consideram os comportamentos, saberes, modos de fazer, técnicas, conhecimentos e valores, sendo a cultura transmitida entre gerações e no interior dos grupos humanos (CLAVAL, 2007).

O autor defende que a cultura está presente na constituição de identidades desde a "primeira infância" (CLAVAL, 2014, p. 72) por meio dos sentidos. Posteriormente, essa mesma identidade cultural é estabelecida pela transmissão de novos códigos. Assim, Claval (2014, p. 190) afirma que o "sentimento de identidade" favorece o "sentimento de territorialidades". Posto isto, podemos significar território como espaço de relações e territorialidade como espaço vivido.

Tomar a cidade como um território na perspectiva cultural nos conduz às contribuições de Michel de Certeau e colaboradores (2012; 2013; 2014), que nos remetem à cidade observada a partir do cotidiano, por meio de várias práticas dos seus habitantes.

Do modo como interpretamos as contribuições do autor, permitimo-nos afirmar que Certeau (2012) também expressa uma concepção territorial valorizando o cotidiano e as 
relações sociais. Ao abordar o bairro, o autor possibilita-nos, além de visualizar os espaços, identificar as relações que ali se estabelecem: "o bairro é o espaço de uma relação com o outro como ser social" (CERTEAU, 2012, p. 43), o que nos remete à cultura como uma prática constituindo o território (CLAVAL, 2014).

Certeau apresenta uma cidade viva que olha, respira, chora e está em constante movimento; uma cidade que é feita e refeita por meio do seu cotidiano que "se inventa com mil maneiras de caça não autorizada" (CERTEAU, 2014, p. 38). A cidade que vive a vida de seus habitantes e esses a constroem cotidianamente a partir de suas trajetórias, pois "o espaço assim tratado e alterado pelas práticas se transforma em singularidades aumentadas e em ilhotas separadas" (CERTEAU, 2014, p. 168).

As leituras que fizemos das contribuições de Certeau (2012; 2014) nos oportunizam conceber que as práticas cotidianas, trajetos e espaços de relação, se constituem por meio dos praticantes ordinários, que também somos nós. Pessoas do dia a dia que organizam a vida a partir das necessidades, constituindo as trajetórias como algo cultural e, dessa forma, formando cotidianamente territorialidades.

Para apreender o bairro como território educativo neste estudo de base qualitativa, apoiamo-nos nas contribuições do autor e seu grupo de pesquisa (CERTEAU, 2013; 2014) que apresentam o modo como buscavam capturar as práticas cotidianas de moradores em bairros parisienses, por meio dos trajetos percorridos pelos usuários do bairro, pessoas comuns que protagonizavam, a partir de suas escolhas, diferentes cenas do cotidiano, evidenciando que um território se constrói pela narrativa (CERTEAU, 2014).

Realizamos assim, um processo de observação caminhante, também denominado por Lopes (2007) de metodologia andante. $\mathrm{O}$ autor afirma que essa forma de andar convoca o pensamento reflexivo capaz de captar o visível (materialidade do espaço urbano) e "o invisível (memórias, sentimentos, sentidos)" (LOPES, 2007, p. 73). Nossa intenção com essa opção metodológica foi traçar uma cartografia de processo, por meio da qual buscamos apreender territórios educativos, no bairro São Paulo, na cidade de Governador Valadares.

A cidade localiza-se na região leste do estado de Minas Gerais e contava, em 2010, de acordo com o Censo do Instituto Brasileiro de Geografia e Estatística (IBGE) ${ }^{\mathrm{ii}}$, com população estimada em 263.689 habitantes e, para o ano de 2017, a estimativa desse mesmo Instituto foi de 280.901 habitantes.

A cidade se constrói às margens do rio Doce que a corta e garante à população a água potável. O rio Doce, ao mesmo tempo que é fonte de vida, memórias e práticas culturais, foi vitimado em 2015 pelo desastre ambiental provocado pela Mineradora Samarco iii. Esse fato suscita aos valadarenses a envidar esforços coletivos para a recuperação do rio e pela preservação ambiental, frente ao cenário de degradação ambiental acirrado pela lama de rejeitos de minério que o atingiu (ESPINDOLA et al. 2016; CAMPOS et al. 2017).

A escolha do bairro São Paulo como lócus de pesquisa foi motivada pelas memórias afetivas de um dos pesquisadores; por ser este um bairro recortado pelo rio Doce e por contar com duas escolas públicas: uma escola que atende ao ensino fundamental (anos iniciais e finais) e ao ensino médio, funcionando em tempo parcial e uma que oferece a educação 
infantil e os nove anos do ensino fundamental, funcionando desde 2010 como Escola em Tempo Integral (GOVERNADOR VALADARES, 2009).

O primeiro exercício foi o de nos reconhecermos como praticantes da cidade e, assim, construímos um itinerário de buscas por fontes documentais sobre o bairro escolhido, o que nos levou a diferentes espaços públicos (Secretarias Municipais de Educação, de Cultura, de Planejamento e Administração da Prefeitura Municipal de Governador Valadares, Museu da Cidade, Biblioteca Pública e Centro Cultural que abriga documentos sobre a cidade). Na literatura sobre Educação Integral/Tempo Integral editada como apoio ao PME, as fontes documentais sobre a cidade e sobre o bairro, possibilitam delinear territórios educativos, por meio do já produzido em "arquivos e bibliotecas. Documentos, mapas, fotografias, filmes, cartas e outros registros podem ajudar nesse levantamento" (BRASIL, 2009b, p. 11).

Complementando esse exercício, buscamos também nos inserir neste bairro por meio de caminhadas, buscando identificar equipamentos urbanos e apreender um pouco as práticas cotidianas no bairro, pela ótica do direito à cidade e da constituição dos territórios pelos praticantes.

\section{Cartografando territórios educativos no bairro São Paulo}

Para cartografar territórios educativos no bairro, buscamos traçar a cartografia do bairro inspirados em Paul Claval (2014), que nos desafia a elaborar mapas temáticos. Esse tipo de mapa, na proposta do autor, é diferente dos mapas presentes nos atlas geográficos, pois nele busca-se captar memórias, práticas e o olhar de quem vive o lugar. Para captar esse olhar, nos aproximamos também de Michel de Certeau que nos mostra o bairro como lugar praticado. Assim, buscamos reconhecer o bairro naquilo que a cidade contava sobre ele e o vivido pelos seus praticantes ordinários, pessoas comuns que imprimem no bairro as marcas da territorialidade. São esses resultados que apresentamos nas seções a seguir.

\section{Bairro São Paulo: memórias e direito à cidade}

A busca documental sobre o bairro em análise revelou-se infrutífera. Não tivemos sucesso nos locais que tradicionalmente poderiam ter informações sobre esse bairro, especialmente, aspectos da memória ou informações mais atuais como as praças, número de habitantes, associações e outros grupos de trabalho ou culturais, organizados no bairro, ou a relação escola/bairro cujo silenciamento se apresenta nos documentos orientadores da ETI ${ }^{\text {iv }}$. No Museu da Cidade localizamos um arquivo com diversos bairros, distritos e ruas da cidade, contendo uma série de reportagens ${ }^{\mathrm{v}}$ publicadas no Jornal Diário do Rio Doce ${ }^{\mathrm{vi}}$, referentes ao ano de 2006, e algumas pastas contendo adendos de outras matérias publicadas posteriormente. Dentre esses documentos, encontrava-se uma reportagem sobre o bairro São Paulo. 
Considerando que a reportagem era do ano de 2006, fizemos outras buscas eletrônicas sobre o bairro, mas o que encontramos, de modo geral, foi a denúncia sobre a violência como uma das dificuldades do bairro.

Para capturar a memória do bairro, buscamos documentos na Igreja Católica situada na comunidade e uma das mais antigas do local, bem como na Associação dos Moradores do Bairro São Paulo (AMASP), que funciona desde 2001, mas não encontramos informações e registros sobre a história local.

Também buscamos informações na Câmara Municipal da cidade, mas sem sucesso, pois não foram encontrados documentos sobre a criação do bairro, a não ser, leis que criaram nomes de praças e doação de lotes. A Secretaria Municipal de Planejamento nos informou que o bairro se chamava Vila Placidina e que só se tornou bairro São Paulo, em 1963.

O bairro São Paulo, destacado em vermelho no mapa abaixo, está localizado às margens do rio Doce, fazendo divisa com outros bairros da cidade.

Figura 1. Mapa do bairro São Paulo em destaque de vermelho

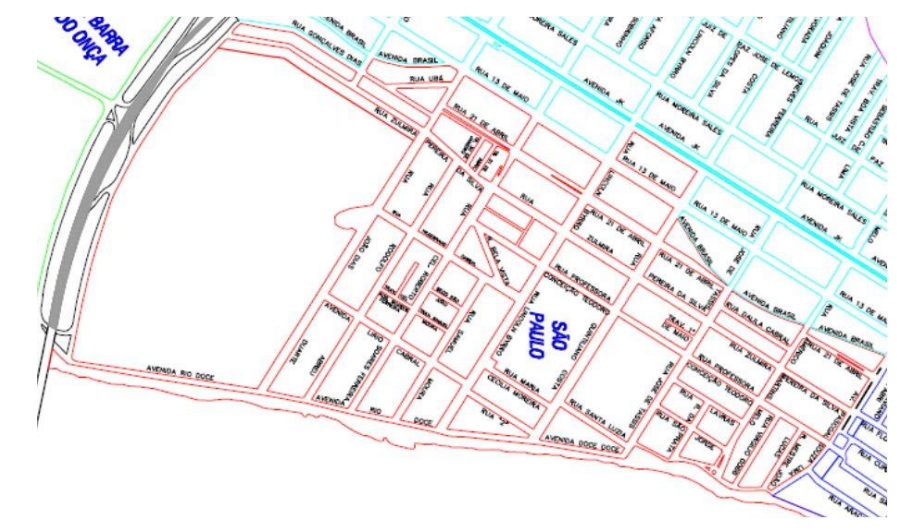

Fonte: Secretaria Municipal de Saúde de Governador Valadares.

Com 54 anos de existência, o bairro se configura entre os dez bairros com maior população da cidade, totalizando 7.471 moradores: 3.433 homens e 4.038 mulheres, retratando assim, um percentual de $45,95 \%$ do sexo masculino e $54,05 \%$ do sexo feminino, indicando uma predominância feminina no local (IBGE, 2010).

Comparando as informações contidas no Censo 2010 entre idosos e jovens moradores do bairro São Paulo, observamos que a população juvenil atingia, aproximadamente, 1600 moradores, enquanto a população idosa contava com 800 moradores, ou seja: $12 \%$ da população eram de idosos e $24 \%$ de jovens (IBGE, 2010).

No quesito equipamentos urbanos e espaços públicos, conforme dados coletados nas Secretarias Municipais de Planejamento e Administração, encontramos: duas equipes de Estratégia de Saúde da Família (ESF); duas praças comunitárias (Praça Cícero Siqueira e Praça da Paz); na Secretaria Municipal de Educação e na $13^{a}$ Superintendência Regional de Ensino constavam registros de três escolas públicas: Centro Municipal de Educação Infantil 
(CEMEI) que atende crianças de 02 anos até 05 anos de idade; escola de Ensino Fundamental (EF) - Anos Iniciais e Finais; escola de EF e Médio, já citadas.

Além desse conjunto de dados, identificamos na reportagem publicada no Jornal Diário do Rio Doce, em 29 de janeiro de 2006, que o bairro possuía 45 ruas, dois campos de futebol (Campo da Liga de Futebol Amador e COOPEVALE Futebol Clube) e abrigava ainda o Parque de Exposições, palco de grandes eventos da cidade (religiosos e shows), além de ser utilizado para promover anualmente a Exposição Agropecuária da cidade (JORNAL DRD, 2006). Esses espaços ainda existem, como comprovado nas caminhadas.

Se pensarmos o bairro pela ótica do direito à cidade, ele possui equipamentos e espaços potencialmente educativos por meio dos quais os moradores têm acesso à educação, saúde, lazer e atividades culturais. Entretanto, a reportagem disponível reivindicava, em 2006, maior atenção do poder público para as ruas e praças e destacava preocupação com a violência: "A marginalidade também é vista como um problema [...]" (JORNAL DRD, 2006). Assim, de acordo com a reportagem, o direito à cidade já não se fazia de modo pleno para os moradores, o que nos conduz a refletir sobre os avanços a esse direito no bairro, após 10 anos.

\section{Um praticante ordinário no Bairro}

Compreendendo que "a caminhada afirma, lança suspeita, arrisca, transgride, respeita etc, as trajetórias que "fala" (CERTEAU, 2014, p. 166, grifos do original), buscamos ficar atentos às trajetórias que ali se faziam. Caminhar, então, é um ato de enunciação que, ao ser declarado nos passos, nas conversas, nas observações, nos relatos, produz o território sobre o qual anda.

Foram 07 caminhadas que variavam entre uma hora e trinta minutos a três horas, dependendo do itinerário, das paradas e das conversas estabelecidas. Buscamos capturar o bairro São Paulo, os atores sociais, os territórios educativos e apreendermos um pouco desse lugar por meio dos seus praticantes. As andanças se deram em dias e horários alternados, a partir de um trajeto definido anteriormente (foram utilizados trajetos ditados pela memória do pesquisador, antigo morador e outros que buscaram escapar desses caminhos usuais).

As percepções do caminhar foram registradas em um diário de campo, bem como diálogos ocasionais que ocorriam de forma espontânea, outros intencionais. As caminhadas foram mapeadas por aplicativo de celular "Strava". As figuras abaixo retratam as caminhadas 01 e 02 . 
Figura 2. Trajeto da primeira caminhada

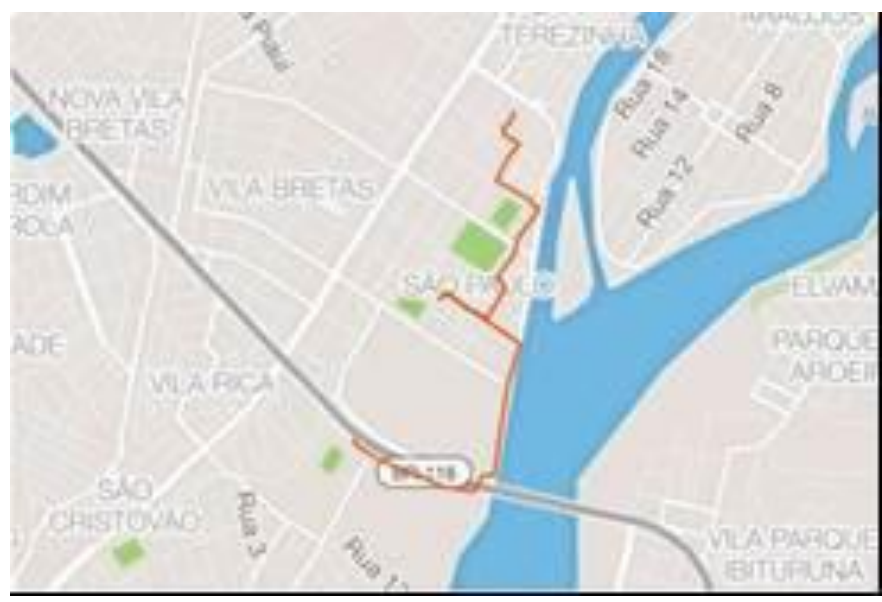

Fonte: Imagem capturada por meio do programa Strava

Figura 3. Trajeto da segunda caminhada

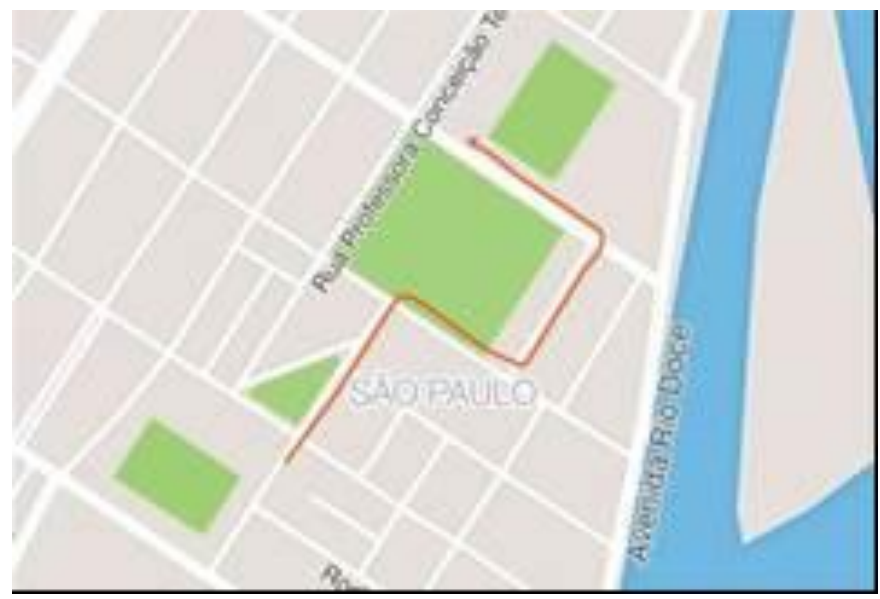

Fonte: Imagem capturada por meio do programa Strava

Certeau (2013), ao discutir práticas de morar e cozinhar em um bairro, argumenta que este é o lugar “onde se manifesta um 'engajamento' social ou, noutros termos: uma arte de conviver com parceiros (vizinhos, comerciantes) que estão ligados a você pelo fato concreto, mas essencial, da aproximação e da repetição" (CERTEAU, 2013, p. 39, grifos do original).

O autor nos inspira na análise do bairro para além das delimitações físicas, reconhecendo-o como um território (CLAVAL, 2012; 2014) onde ocorrem diversas práticas culturais cotidianas de seus moradores. O bairro é, pois, território de relações do cotidiano, das linguagens, do contato, do reconhecimento, do trabalho, dos itinerários, dos encontros dos habitantes de um mesmo território. Com esse olhar, foram lidos os registros do diário de campo e destacamos praças e ruas desertas, bem como práticas cotidianas que conseguimos apreender. 


\section{Praças e ruas desertas}

No exercício de caminhar em dias e horários diferentes, foi possível observar o fenômeno das praças e ruas desertas.

A praça, como argumenta Moll (2012; 2014), é território educativo. Reconhecemos a praça como tal por ser parte da vida de um bairro, espaço livre a ser utilizado por todos, local de encontro de diferentes grupos, vivificada por práticas cotidianas. Mas, nesse bairro, as praças encontravam-se esvaziadas. Lembramos que para se converter em território educativo a praça necessita ser apropriada pelos atores que nela imprimem suas marcas. Assim, nas diferentes andanças, as praças do bairro foram incluídas no itinerário. Nessas andanças chamou-nos a atenção o seu esvaziamento (ausência de famílias, crianças, adolescentes e jovens).

Chegamos à Praça Cícero Siqueira que estava deserta e constatamos o abandono pelo poder público. Há de se convir, que a comunidade também não 'cuida' daquele espaço que deveria ser de convivência. Além disto, dois cavalos se alimentavam da vegetação seca que brotava entre as pedras (DIÁRIO DE CAMPO, 2017).

Assim, o que poderia ser um local de encontro vai se tornando vazio. A ausência de lâmpadas nos postes, como foi observado, inviabiliza a ocupação à noite. Essa praça é passagem de estudantes do Ensino Médio que precisam atravessá-la à noite, portanto, "no escuro". Nesse sentido, o relato dessa observação é também uma denúncia social em relação ao poder público, pelo não cumprimento de suas obrigações na conservação do patrimônio público, bem como no cuidado com o bairro, principalmente em relação às praças.

Em outra caminhada, fizemos um itinerário em algumas ruas próximas à igreja católica, continuamos em direção às praças e o fenômeno se repetia. Empreendemos caminhadas de segunda-feira à sexta-feira sem encontrar as praças ocupadas. Assim, realizamos uma nova caminhada, sábado à tarde, em direção às duas praças:

Ainda estou em busca das crianças, adolescentes jovens do bairro São Paulo. Onde estarão? São 17h45, chego à Praça da Paz. Está um dia ameno. A praça encontra-se vazia. Sem vida, sem pessoas, sem animais. Parece um "elefante branco". Não há ninguém, dia triste [...] (DIÁRIO DE CAMPO, 2017).

Optamos também por realizar a caminhada em um domingo, mas "as pessoas passavam pelas praças e ninguém parava" (DIÁRIO DE CAMPO, 2017). O esvaziamento das praças e os poucos relatos parecem indicar que praça não se configura como um território de pertencimento no bairro. Outro aspecto que é válido mensurar, refere-se à relação escola, bairro e espaços públicos, de forma precípua à utilização da Praça da Paz, localizada em frente às escolas públicas do bairro.

Uma professora da escola, encontrada em uma das andanças e conhecida do pesquisador, relatou que a escola que funciona em tempo integral utiliza a praça, preferencialmente pela manhã, para atividades diversas, como espaço de leitura, aulas de percussão e aulas de música. 
A opção pela ocupação da praça pela escola, no caso das aulas de percussão e música, foi definida por não ter um espaço interno adequado e o barulho dos instrumentos interferir na dinâmica da escola. No caso da biblioteca, a ausência de espaço interno também justifica o uso da praça pela escola. Assim, a praça parece não ser tomada como território a ser apropriado, mas a ocupação do espaço é justificada pela fragilidade arquitetônica da escola, o que se constituiu uma dificuldade, de modo geral, nas experiências de tempo integral no Brasil (BRASIL, 2010b). A escola ocupa assim, o espaço da praça, em dias e horários determinados em ações de escolarização, o que esperamos que contribua para outros olhares sobre esse espaço - de defesa, de convite à ocupação dos moradores, ou ainda na promoção de outras ações, via escola, que estimulem o habitar a praça.

Em nossas andanças buscamos indícios da relação escola/bairro e atentos aos movimentos das escolas com os estudantes nas ruas e praças, não nos foi possível identificar atividades extramuros. Por isso nos concentramos em observar a saída dos estudantes das escolas na tentativa de identificar como eles se apropriavam da praça. Acompanhamos pela manhã, ao final da aula, estudantes da escola de tempo parcial e percebemos que "eles começavam a sair em pequenos grupos, alguns a pé, outros de bicicletas, outros paravam um pouco, formavam grupos na rua interferindo no tráfego" (DIÁRIO DE CAMPO, 2017), mas não se dirigiam à praça. À tarde, acompanhamos o movimento de saída dos estudantes em tempo integral e eles permaneciam um tempo na praça:

\footnotetext{
se apropriando daquele território, correndo, brincando, conversando, fazendo o Salto Streck, mais conhecido como pirueta. Por ali, eles ficaram cerca de $1 \mathrm{~h}$ a $1 \mathrm{~h}$ e 10 min. Achei muito interessante que, mesmo próximo deles, sentando embaixo de uma árvore, eles me pareciam à vontade pelo modo como brincavam, conversavam ocupavam aquele espaço (DIÁRIO DE CAMPO, 2017).
}

Nessa praça também se localiza um posto policial, que por um lado pode ser uma ação protetiva, mas por outro pode restringir o acesso à praça, pela presença das viaturas estacionadas (às vezes na pista de caminhada que contorna a praça), como foi possível flagrar nas andanças.

Além das praças, não identificamos grupos de pessoas conversando na porta das casas, por exemplo, ou pessoas passeando com crianças, ou animais. O movimento de circulação é marcado pelos automóveis.

Uma possível explicação para a pouca ocupação do espaço urbano no bairro pode ser a violência, posto que a cidade de Governador Valadares tem comparecido em estatísticas nacionais com alto índice de violência envolvendo jovens (IPEA, 2017). Um estudo realizado por Santos (2012), que apresenta dados de crimes violentos ${ }^{\mathrm{vii}}$ na cidade de Governador Valadares (biênio 2010-2011), localiza o bairro em duas posições: $7^{\circ}$ posição, quando referese à residência dos autores desses crimes; $10^{\circ}$ posição, quando diz respeito às residências das vítimas que sofrem o crime.

As questões da vulnerabilidade juvenil e da violência têm comparecido nas discussões sobre educação integral/tempo integral no binômio educação/proteção de crianças, adolescentes e jovens e a escola é tomada como um espaço protetor (BRASIL, 2010a; MOLL, 2012). Refletir sobre territórios educativos neste estudo é estar alerta para a pouca 
apropriação dos espaços do bairro por aqueles que deveriam ser seus praticantes ordinários, e sobre a importância da educação integral/tempo integral como possibilidade de reeducar a cidade para a garantia do direito do uso do espaço público.

\section{Práticas cotidianas no bairro}

Fazer as caminhadas no bairro São Paulo não foi fácil, pois, conforme afirma Certeau (2014, p. 175), "estamos ligados a este lugar pelas lembranças... É pessoal, isto não interessaria a ninguém, mas enfim é isso que faz o espírito de um bairro". Assim, para o pesquisador e antigo morador, ir ao bairro foi um exercício de memória afetiva.

Nessa primeira caminhada, destacamos um antigo bar do bairro, conhecido como bar do "Geraldo Chifrudo" que tornou-se uma referência pelo nome, bem como, pela apropriação feita por moradores, pois é um "espaço de distração" (CLAVAL, 2014, p. 138), que implica sempre em uma forma de representação no imaginário individual ou social; "um lugar de encontro" (CERTEAU, 2013, p. 57). Esse espaço compõe o cenário do bairro há décadas e o seu proprietário, antigo morador, por meio dos seus relatos, pode ser uma fonte oral da memória do bairro.

Há que se destacar também, a presença da coletividade no bairro. Em uma das andanças encontramos uma associação recente: "Rio Limpo", lugar de parada na caminhada. A Associação desenvolve a fabricação de sabão vegetal a partir do óleo de cozinha descartado e sobrevive em meio a muitos desafios.

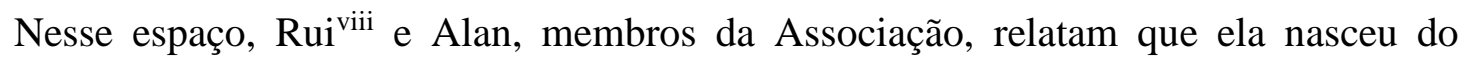
desejo de um grupo de amigos (mulheres e homens), moradores do bairro, preocupados com o meio ambiente, de forma especial com o rio Doce, de criar esse espaço coletivo para fabricação de sabão ecológico. Narraram as dificuldades de se manterem no mercado, em função da concorrência dos grandes produtores de sabão.

\footnotetext{
Estamos aqui mais ou menos. A fábrica está aí, vendendo pouco. Olha aqui para você vê [mostra o panfleto de um supermercado que vende o sabão com valor inferior]. Aquilo, segundo ele, era uma concorrência desleal. Neste instante, chega uma senhora para pagar uma dívida e comprar mais sabão. Perguntei por que eles não vendiam para os supermercados. Eles disseram que para entrar no supermercado tem que dar uma boa quantidade de produtos e a coleta de óleo é pouca. Assim, não teriam condições. Perguntei sobre as receitas e despesas. Alan disse que ultimamente estava pagando somente as despesas, que quase fecharam (DIÁRIO DE CAMPO, 2017).
}

A narrativa acima reafirma as dificuldades deste empreendimento solidário, que talvez venha a ser fechado. No contexto do desastre ambiental citado e pela presença do rio no bairro, a Rio Limpo é um território educativo por sua prática ambiental e poderia, inclusive, fortalecer os cuidados com o rio no bairro.

Em outra caminhada registramos o "dia de feira livre" (quinta-feira) no bairro. Os feirantes contaram, nas conversas realizadas, que a montagem das barracas ocorre bem cedo, às 05 h30. A feira, por si só, constitui um território educativo, pela forma de organização, 
pelos produtos que ali são vendidos (frutas, legumes, verduras, condimentos, biscoitos, farinhas, mel, queijos, esses últimos, muitos são de fabricação local), pelo exercício de comprar, vender, negociar, pelos encontros entre feirantes e feirantes, feirantes e moradores, feirantes e consumidores usuais.

\begin{abstract}
Cheguei por volta das $08 \mathrm{~h} 30$, e encontrei bastante pessoas realizando a sua feira. Homens, mulheres, crianças, jovens e adultos, todos ali em busca de algo: produto ou um hábito de toda quinta-feira. Naquele espaço, vende-se de tudo, da roupa ao peixe, do café moído à fruta e verdura, do sapato à carne de boi e de porco, da farinha ao pastel frito com caldo de cana. Caminhar por aquele corredor gigante, com feirantes vendendo seus produtos em vozes altas, uma disputa interna de quem fala mais alto para alcançar o freguês. Uns falam "olha o tomate"; outros retrucam "olha o tomate fresquinho e barato". E assim vou caminhando, tentando flagrar algumas cenas daquele cotidiano de quinta-feira no bairro (DIÁRIO DE CAMPO, 2017).
\end{abstract}

Além das descritas acima, são várias as cenas que podem ser capturadas: a mãe que conduz as duas filhas pequenas, aparentemente com cerca de sete e nove anos, ajudando-a naquela tarefa:

\begin{abstract}
A mãe incentiva as crianças a fazerem contas na barraca de fruta. A mãe diz: "quanto é a maçã?" O feirante responde: "R \$ 5,00 o quilo". A mãe dá $\mathrm{R} \$ 10,00$ ao feirante e pergunta para a filha: "quanto ele me dará de troco?" A garota se enrola e a outra responde: "cinco reais né". Feira livre, espaço de conhecimento (DIÁRIO DE CAMPO, 2017).
\end{abstract}

A orla do rio Doce foi palco de uma das caminhadas e constatamos o abandono da orla e o descarte de lixo no local. Sobre o rio, não conseguimos identificar projetos de preservação, por parte da Administração Pública ou pela AMASP. Há informações, por meio do jornal impresso local, que ocorreu plantio de mudas de árvores, por meio de cooperação técnica entre a Prefeitura e a AMASP, com participação das crianças do CMEI.

A caminhada denuncia o descaso ambiental e os problemas do rio, como a água ainda com coloração forte em função da lama de rejeitos advinda do desastre ambiental que trouxe prejuízos "à fauna, à flora e à vida das pessoas que habitam na bacia hidrográfica do rio Doce" (CAMPOS et al. 2017, p. 68) e alertam para o fato de que escolas ribeirinhas na cidade devem estar atentas para o não esquecimento do desastre e para o desenvolvimento de ações de defesa do rio.

Nas caminhadas estivemos atentos, também, aos atores sociais que realizam no cotidiano ações educativas. Assim, foi possível flagrar o "José da Padaria" que acolhe as crianças com um super bom dia pela manhã, a Marta, antiga moradora e associada da Rio Limpo, que conversa com os alunos sobre a escola dizendo: "não falte", enquanto se dirige ao trabalho.

Este bairro, conforme apresentam os dados, é mais feminino do que masculino e é um bairro jovem. Tais constatações indicam a necessidade de outros estudos sobre os jovens (onde estão, o que fazem, os grupos dos quais participam, como praticam a rua). Defendemos, também, que a escola pode e deve se apropriar do bairro na relação bairroescola, aprendendo a captar a vida do bairro e buscando transformações nesse espaço para que ele se converta em território educativo. 
Nesta seção, apresentamos algumas práticas cotidianas no bairro, mesmo sabendo que outras práticas não foram captadas, considerando os limites da pesquisa. Como antigo morador do bairro, foi possível constatar muitas mudanças, dentre elas, as praças e ruas vazias e as pessoas restritas à casa, ao trabalho e à escola. Além disso, a memória do bairro parece esquecida pela ausência de documentos que apresente a história do bairro. Sabemos que outras tantas práticas cotidianas ali devem ocorrer e este exercício analítico reafirma a importância de uma maior atenção das escolas para com o bairro, fortalecendo o argumento da educação integral.

\section{Conclusão}

Neste artigo, fizemos um exercício de cartografar territórios educativos em um bairro, visando contribuir com o debate da ampliação da jornada escolar em um maior diálogo com a cidade. Pensar a cidade como constituída de territórios educativos nos convoca a um olhar mais atento para as praças, ruas, bairros, na tentativa de apreender como a cidade, com seus diferentes territórios e atores, educa.

Consideramos importante refletir que a cidade é espaço de direito de todos e todas. Este direito parte do pressuposto de que são necessárias atitudes como a participação popular e uma gestão pública eficiente. Uma cidade se faz educadora pelo acesso aos equipamentos urbanos: unidades de saúde, escolas, creches, esporte e lazer, serviços de abastecimento, segurança pública, dentre outros que possam contribuir com a aprendizagem de crianças, adolescentes, jovens e adultos.

O nosso exercício de apreender territórios educativos revelou-se desafiador pela ausência de documentos sobre o bairro. Nesse sentido, o diálogo escola/bairro pode contribuir para organização de um acervo sobre o bairro, por exemplo, buscando a memória dos antigos moradores, os saberes da comunidade e dos grupos que ali se organizam, as formas de expressão da comunidade com vista à educação patrimonial (BRASIL, 2009b). Nessa perspectiva, a ETI pode contribuir promovendo o diálogo entre a Secretaria Municipal de Educação e outras secretarias e órgãos responsáveis pela cultura e pela memória.

O exercício de caminhada feito neste estudo pode inspirar o traçado de diversas trajetórias com estudantes, buscando apreender os diversos caminhos de um bairro - os usuais e os menos usuais; é possível perceber, nessas caminhadas, a vida cotidiana e os atores que dão vida aos diferentes territórios no bairro; debater juntamente com os caminhantes o que pode ser considerado educativo, bem como as mazelas e dificuldades do local. Esse é um exercício de aguçar o olhar para captar também, como os direitos à moradia, saúde, acessibilidade às ruas, saneamento básico, dentre outros, se efetivam no bairro. Essa captura pode provocar ricos debates, portanto, aprendizagens cidadãs para estudantes e docentes. 


\section{Referências}

BRASIL. Constituição 1988. Constituição da República Federativa do Brasil. Brasília, 1988.

BRASIL. Lei no 9.394, de 20 de dezembro de 1996. Estabelece as Diretrizes e Bases da Educação Nacional. Diário Oficial da República Federativa do Brasil, Brasília, DF, v. 134, n. 248, 23 dez. 1996.

BRASIL. Portaria Interministerial no . 17, de 24 de abril de 2007. Institui o Programa Mais Educação. Diário Oficial da República Federativa do Brasil, Brasília, DF, n. 17, 24 abr. 2007.

BRASIL. Educação integral: texto referência para o debate nacional. Brasília, 2009a.

BRASIL. Educação Patrimonial: Programa Mais Educação. Brasília, 2009b.

BRASIL. Decreto Federal $\mathbf{n}^{\mathbf{0}} \mathbf{7 . 0 8 3}$, de 27 de Janeiro de 2010. Dispõe sobre o Programa Mais Educação. Brasília, 2010a.

BRASIL. Educação integral/educação integrada e(m) tempo integral: concepções e práticas na educação brasileira. Mapeamento das experiências de jornada escolar ampliada no Brasil: estudo quantitativo. Brasília, 2010b.

BRASIL. Lei no 13.005, de 25 de junho de 2014. Aprova o Plano Nacional de Educação PNE e dá outras providências. Brasília, DF, 26 jun. 2018.

BRASIL. Portaria n⿳ 1.144, de 10 de outubro de 2016. Institui o Programa Novo Mais Educação, que visa melhorar a aprendizagem em língua portuguesa e matemática no ensino fundamental. Brasília, DF, 11 out. 2016.

CAMPOS, Renata Bernardes Faria et al. Risco, desastre e educação ambiental: a terceira margem do rio Doce. Revista PerCursos, Florianópolis, v. 18, n. 36, p. 66-94, jan./abr. 2017.

CAVALIERE, Ana Maria. As zonas de educação prioritária francesas: repercussões e paralelos no Brasil. In: MAURÍCIO, Lúcia Velloso (org.). Tempos e espaços escolares: experiências, políticas e debates no Brasil e no mundo. Rio de Janeiro: Ponteio: FAPERJ, 2014. p. 147-164.

CERTEAU, Michel de. A cultura no plural. $7^{\text {a }}$ ed. Campinas, SP: Papirus, 2012.

CERTEAU, Michel de. A invenção do cotidiano: 1. Artes de fazer. Tradução de Ephraim Ferreira Alves. 22 ed. Petrópolis, RJ: Vozes, 2013.

CERTEAU, Michel de. A invenção do cotidiano: 2. Morar, cozinhar. Tradução de Ephraim Ferreira. 12 ed. Petrópolis, RJ: Vozes, 2014.

CLAVAL, Paul. A Geografia Cultural. 3 ed. Florianópolis: Ed. UFSC, 2007. 
CLAVAL, Paul. A geografia cultural no Brasil. In: BARTHE-DELOIZY, Francine; SERPA, Angelo (org.). Visões do Brasil: estudos culturais em Geografia. Salvador: EDUFBA; 2012. p. 11-25.

CLAVAL, Paul. Epistemologia da Geografia. 2 ed. Florianópolis: Editora UFSC, 2014.

ESPINDOLA, Haruf Salmen et al. Desastre da Samarco no Brasil: desafios para a conservação da biodiversidade. Fronteiras: Jornal of Social, Techonological and Environmental Science. Anápolis, v. 5, n. 3, p. 72-100, jul./dez. 2016.

GOVERNADOR VALADARES. Secretaria Municipal de Educação. Escola em Tempo Integral. Caderno 1. Governador Valadares, 2009.

IBGE. Panorama população 2010. Disponível em: https://cidades.ibge.gov.br/brasil/mg/governador-valadares/panorama. Acesso em: 18 mar. 2018.

INEP. Censo Escolar da Educação Básica 2016. Notas Estatísticas. Brasília, DF, fev. 2017. Disponível em: encurtador.com.br/akz59. Acesso em: 08 jan. 2018.

IPEA. Atlas da violência 2017. Disponível em: http://www.ipea.gov.br/portal/images/170609_atlas_da_violencia_2017.pdf. Acesso em: 18 mar. 2018.

LEFEBVRE, Henri. A revolução urbana. Belo Horizonte: Ed. da UFMG, 1999.

LEFEBVRE, Henri. O direito a cidade. São Paulo: Centauro, 2001.

LOPES, João Teixeira. Andante, andante: tempo para andar e descobrir o espaço público. Sociologia, Revista da Faculdade de letras da Universidade do Porto, Porto, v. 17, p. 6980, 2007. Disponível em: http://ojs.letras.up.pt/index.php/Sociologia/article/view/2345. Acesso em: 24 abr. 2018.

MOLL, Jaqueline (org.). Caminhos da Educação Integral no Brasil: direito a outros tempos e espaços educativos. Porto Alegre: Penso, 2012.

MOLL, Jaqueline. Mais Educação e PIBID: intersecções entre agendas estruturais para a Educação Brasileira. In: SIMÕES, Regina; BARBOSA, Juliana Bertucci; MOREIRA, Wagner Wey (org.). Escola em Tempo Integral: linguagens e expressões. 1 ed. Uberaba: UFTM, 2014. p. 17-37.

SANTOS, Wagner Fabiano dos. O território do crime em Governador Valadares: diagnósticos e perspectivas. 2012. 99 f. Dissertação (Mestrado em Gestão Integrada do Território) - Universidade Vale do Rio Doce, Governador Valadares, 2012.

SOUZA, Maria Celeste dos Reis Fernandes; CHARLOT, Bernard. Relação com o saber na Escola de Tempo Integral. Revista Educação e Realidade, Porto Alegre, v. 41, n. 4, p. 10711093, out./dez. 2016. Disponível em: http://www.scielo.br/pdf/edreal/v41n4/2175-6236edreal-59843.pdf. Acesso em: 24 abr. 2018. 
UFMG. Universidade Federal de Minas Gerais. Faculdade de Educação. GRUPO TEIA Territórios, Educação Integral e Cidadania. Relatório do Projeto de Avaliação e Monitoramento do Programa Escola de Tempo Integral (ETI) da Secretaria Municipal de Educação de Governador Valadares - MG. Belo Horizonte, 2012.

\section{Notas}

i Conferir: www.cidadeseducadoras.org.br. Acesso em: 18 jun. 2018

ii Disponível em: https://cidades.ibge.gov.br/v4/brasil/mg/governador-valadares/panorama. Acesso em: 18 jun. 2018.

iii Empresa responsável pelo desastre ambiental.

iv Buscamos identificar na Secretaria Municipal de Educação referências aos bairros em Projetos Políticos Pedagógicos das escolas, ou outros documentos que trouxessem informações sobre os bairros.

" Série publicada no Jornal Diário do Rio Doce - "Nosso Bairro".

vi Jornal Diário do Rio Doce, jornal local da cidade.

vii "São considerados como crimes violentos, para fins de análises criminais, os delitos de homicídio consumado e tentado, o roubo consumado, o roubo à mão armada consumado (assalto), o estupro tentado, o estupro consumado, o sequestro e cárcere privado, o roubo seguido de morte (latrocínio) e a extorsão mediante sequestro" (SANTOS, 2012, p. 18).

viii Os nomes foram substituídos para preservar a identidade dos sujeitos. 